\title{
Vitamin D levels in patients presenting to a gastroenterology clinic
}

\author{
M. Yousif ${ }^{1}$, B. S. Höroldt ${ }^{1}$, M. Srinivas ${ }^{1}$, P. J. A. Willemse ${ }^{1}$, P. Basumani ${ }^{1}$, R. Ellis ${ }^{2}$ \\ and K. D. Bardhan ${ }^{1}$ \\ Departments of ${ }^{1}$ Gastroenterology and ${ }^{2}$ Clinical Chemistry, Rotherham General Hospital NHS Foundation Trust, Moorgate, \\ Rotherham S60 2UD, UK
}

Vitamin D deficiency is associated with non-specific symptoms, carries long-term risk to bone health, and certain groups are at higher risk (alcohol excess, old age, Asians). The prevalence and seasonal variation amongst patients attending gastroenterology clinics is unclear; this prompted our pilot study.

Patients ( $n$ 556), randomly chosen, with alcoholic liver disease (ALD; $n$ 52), inflammatory bowel disease (IBD; $n$ 110), irritable bowel syndrome (IBS $n$ 174), other liver disease ( $n$ 50), iron deficiency anaemia (IDA) ( $n$ 49), other diagnosis $(n$ 121). Use of over the counter supplements was checked and those on vitamin preparations excluded. Measurements were of: Vitamin D (25-(OH) Vitamin D3), Ca profile, $\mathrm{Mg}$, ferritin, $\mathrm{B}_{12}$ and folate. There were 315 females of which thirty-six were Asian. Median age was 55 (range18-86) years. Results (see Table) were as follows:

1. Only $35.3 \%$ had adequate levels.

2. Severe deficiency was most frequent in ALD (52\%), other liver disease (33\%) and IDA (37.5\%) (27\% overall). Mild-moderate deficiency occurred in similar frequency ALD (29\%), other liver disease (42\%) and IBD (44\%), but also in IBS (35\%).

3. Severe/moderate deficiency occurred significantly more often in Asians $(P=0.0041)$ and older people $(>60 /<60$ yrs; $P=0.0 .30)$, but was unrelated to sex $(P=0.4917)$ (all Fisher's exact test).

4. Median vitamin level showed little seasonal variation; April-September $(40 \mathrm{nmol} / \mathrm{l})$ and October-March $(41.7 \mathrm{nmol} / \mathrm{l})$.

5. Deficiency in folate, vitamin $B_{12}$ and iron was 10,16 and $9 \%$ respectively (excluding patients referred with a deficiency).

\begin{tabular}{|c|c|c|c|c|c|}
\hline \multirow[b]{2}{*}{ Condition } & \multirow[b]{2}{*}{$n$} & \multirow[b]{2}{*}{$\begin{array}{l}\text { Median vitamin D } \\
\text { level }(\mathrm{nmol} / \mathrm{l})\end{array}$} & \multicolumn{3}{|c|}{ Number of patients (\%) with deficiency } \\
\hline & & & $\begin{array}{c}<25 \mathrm{nmol} / \mathrm{l} \\
\text { Severe }\end{array}$ & $\begin{array}{c}25-50 \mathrm{nmol} / \mathrm{l} \\
\text { Mild-moderate }\end{array}$ & $\begin{array}{l}>50 \mathrm{nmol} / \mathrm{l} \\
\text { Adequate }\end{array}$ \\
\hline All & 556 & 41 & 26.5 & 38.1 & 35.3 \\
\hline ALD & 52 & 22 & 52.1 & 33.3 & 14.6 \\
\hline Liver & 50 & 31 & 33.3 & 41.7 & 25.0 \\
\hline IBD & 110 & 45 & 22.8 & 43.6 & 33.6 \\
\hline IBS & 174 & 49.5 & 18.9 & 34.5 & 46.6 \\
\hline Other & 121 & 41 & 24.0 & 42.2 & 33.8 \\
\hline IDA & 49 & 33 & 37.5 & 29.2 & 33.3 \\
\hline
\end{tabular}

We conclude, that:

1. Vitamin D deficiency is common in patients attending gastroenterology clinics, is almost always subclinical and its long-term significance is unknown.

2. The seasonal variation is less than expected.

3. Increasing awareness has allowed us to recognise the condition more often. 